\title{
Development of metal-graphene-filled hybrid composites: Characterization of mechanical, thermal, and electrical properties
}

\author{
Doagou Rad, Saeed; Islam, Aminul; Alnasser, Ammar
}

Published in:

Journal of Composite Materials

Link to article, DOI:

$10.1177 / 0021998318812928$

Publication date:

2019

Document Version

Peer reviewed version

Link back to DTU Orbit

Citation (APA):

Doagou Rad, S., Islam, A., \& Alnasser, A. (2019). Development of metal-graphene-filled hybrid composites: Characterization of mechanical, thermal, and electrical properties. Journal of Composite Materials, 53(24), 3363-3376. https://doi.org/10.1177/0021998318812928

\section{General rights}

Copyright and moral rights for the publications made accessible in the public portal are retained by the authors and/or other copyright owners and it is a condition of accessing publications that users recognise and abide by the legal requirements associated with these rights.

- Users may download and print one copy of any publication from the public portal for the purpose of private study or research.

- You may not further distribute the material or use it for any profit-making activity or commercial gain

- You may freely distribute the URL identifying the publication in the public portal 


\title{
Development of Metal - Graphene Filled Hybrid Composites: Characterization of
} Mechanical, Thermal and Electrical Properties

\author{
Saeed Doagou Rad 1,2,a *, Aminul Islam ${ }^{1,2, \mathrm{~b}}$ and Ammar Alnasser ${ }^{2}$ \\ ${ }^{1}$ Centre of Acoustic Mechanical Microsystems (CAMM), Technical University of Denmark, \\ Building 352, DK-2800 Kgs. Lyngby, Denmark \\ 2 Department of Mechanical Engineering, Technical University of Denmark, Produktionstorvet, \\ Building 427A, DK-2800 Kgs. Lyngby, Denmark \\ Phone: +4545254867 \\ Fax: +4545251961 \\ sadora@mek.dtu.dk
}

Keywords: Polymer composites; Nanocomposites; Reinforcements; Processing technologies; Industrial applications.

\begin{abstract}
Production and properties of hybrid Graphene nanoplatelets (GNPs) and metal filled polymeric composites are investigated. Polyamide 6 based composites containing conductive micro and nano fillers are produced through consecutive melt compounding and injection/compression molding processes. Mechanical, electrical, and thermal properties of the produced composites are characterized, and the involved mechanisms are studied. Moreover, the influence of GNPs characteristics on the properties of the composites are also studied. The results show that the thicker and larger GNPs act as more efficient conductivity reinforcement agents. Furthermore, combination of GNPs and metallic micro scale fillers leads to significant improvements in thermal and electrical conductivities. In fact, GNPs act as conductive bridges in minuscule gaps to increase the number of contacts in the constructed network. The combination of the two different fillers increased the mechanical properties of the metal reinforced composites up to $120 \%$ indicating stronger interfaces between the fillers and polymeric matrix. The influence of annealing on the conductivities of the specimens are also studied. Adding an annealing step to the nanofiller inclusion within the composites resulted in 250 and $72 \%$ enhancement in the thermal and electrical conductivities, respectively. Stress relaxation and reorientation of metal fibers in combination with additionally constructed nanofiller
\end{abstract}


networks have been attributed to the observed enhancements. The involved mechanisms in the observed behaviors are studied using optical and electron microscopies.

\section{Introduction}

The realm of conductive polymeric composites (CPCs) has been one of the most interesting topics in polymer research [1-5]. Tunable properties and ease of fabrication into complex structures have made this group of materials invaluable, especially for novel manufacturing and applications. CPCs based on their level of electrical conductivity are being used as antistatic, electrostatic paintings, and electromagnetic interference (EMI) shielding. They have also been used in the novel advanced applications such as sensors, damage monitoring, shape memory materials, thermoelectric materials, and even printed electrical circuits [6]. Moreover, thermally conductive composites have been used in electronic packaging, chip packages, and solar systems [7]. Combination of both electrical and thermal conductivities are desired in electrical circuit applications, additive manufactured molds, and LED devices. Therefore, recent advancements in the technology call for novel multifunctional polymeric materials like electrically and/or thermally conductive plastics that have the potential to be fabricated precisely especially through mass manufacturing processes. Incorporation of conductive fillers within polymers to create conductive networks inside the structure of polymeric composites has been one of the attempts towards this target $[8,9]$.

Different kinds of conductive fillers are used for increasing conductivity in the polymeric composites. Metals fibers, carbon black, carbon fibers, and low melting alloys have been used for creating a conductive network and reaching to the so-called "electrical percolation threshold" in the composites. While reducing the average distance between the fillers is desirable to achieve better conductivities, increasing the content of these fillers in the polymer system after certain contents leads to poor processibility, and degradation of other properties especially mechanical performance [6]. While metallic fillers have traditionally being chosen to achieve conductivity in polymers, their susceptibility to oxidation, corrosion, high densities, and relatively high costs are some of their major drawbacks that cannot be neglected in many applications. The advent of novel nanomaterials with their superior properties has provided new possibilities in this area $[10,11]$. Percolation thresholds in lower contents, lower densities, and superior mechanical, electrical and thermal performances are some of their potential advantages [12]. However, their inclusion within polymers has resulted into electrical conductivities less than polymeric composites reinforced with highly conductive metals such as Copper, Silver, and Aluminum [1]. In fact, application of just one kind of filler in the 
polymeric system does not necessarily lead to the desired electrical conductivities. Therefore, a combination of different conductive fillers with different geometries, properties, and contents has been considered as one of the solutions to achieve the desired conductivity $[8,13-16]$. The idea behind using different kinds of fillers is to construct more effective conductive networks through the whole structure.

Graphene NanoPlatelets (GNPs) due to their extraordinary properties have been considered as one of the main candidates to achieve multifunctional characteristics. Properties such as very high stiffness (Elastic modulus $\sim 0.8 \mathrm{TPa})$, high electrical $(\sim 0.1 \mu \Omega \mathrm{cm})$, and thermal $\left(\sim 6000 \mathrm{~W} / \mathrm{m}^{\circ} \mathrm{K}\right)$ conductivities, etc. have made them interesting for different applications [17,18]. Utilizing these superior properties in the composites has been subject of many studies [19-21]. Graphene as a layer of carbon atoms reflects higher electrical and thermal conductivities than Copper. Therefore, CopperGraphene interfaces and composites have attracted attentions for novel applications [22-24]. Fig. 1 shows a comparison between the electrical and thermal properties of the metallic and carbonic fillers and their corresponding polymeric composites. Despite higher conductivities of carbonic nanofiller, when they have been incorporated within the polymeric matrix, lower conductivities than the metallic fillers have been achieved.

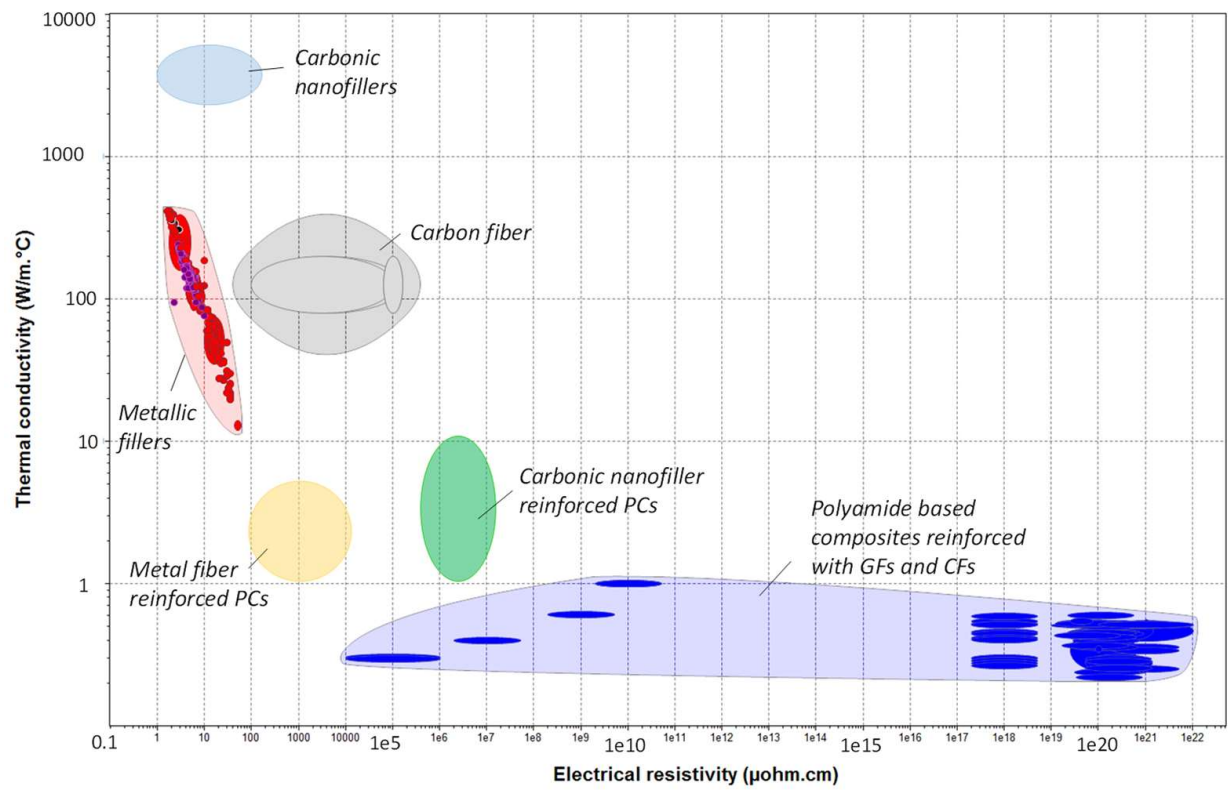

Fig. 1 Thermal and electrical conductivity of the carbonic and metallic fillers and their composites.

The purpose of this study is to produce multifunctional composites with high electrical/ thermal conductivities. The influences of the conductive filler characteristics and content on the behavior of 
the composites are studied. Different composites containing single or combination of conductive fillers are produced using molding processes. Conductive fillers including Graphene nanoplatelets, copper microfibers, and low melting alloys have been incorporated in the Polyamide 6(PA 6) based composites. The mechanical, electrical, and thermal properties of the produced composites are studied in detail. In addition, the influence of annealing as a post-process tool to enhance the conductivity of the composites is studied.

\section{Experiments}

\subsection{Materials}

The Graphene nanofillers used in this study are exfoliated Graphene $\left(\mathrm{XGNP}^{\circledR}\right)$ nanoplatelets from XGSciences, USA. Two types of Graphene namely C-500 and H-15 were used to study the influence of the nanofiller characteristics on the properties of the composites. GNP C-500 nanofillers are small (width $=0.5 \mu \mathrm{m})$ and thin platelets (thickness $=6-12 \mathrm{~nm}$ ), while grade $\mathrm{H}-15$ are larger $($ width $=15$ $25 \mu \mathrm{m})$ and thicker (20-100 nm). A Polyamide or Nylon (PA 6) from BASF, Germany was also used as matrix $\left(\mathrm{T}_{\mathrm{g}}=60^{\circ} \mathrm{C}\right)$. PA 6 Metal filled polymers (Schulatec Tinco 50) were also acquired from A. Schulman GmbH, Germany. The batch is filled with 25 vol. \% micro copper fibers with the average diameter of $45 \mu \mathrm{m}(\mathrm{Cu} 99$, Stax, Germany) covered with 19 vol. \% a low melting Tin-Zinc alloy (MCP 200, 5nplus, Canada).

\subsection{Sample preparation}

To perform the melt compounding of the neat polymer or metal filled composites with Graphene nanofillers, a conical counter rotating twin-screw extruder (HAAKE ${ }^{\mathrm{TM}}$ Rheomex CTW, $\Phi=31.8 / 20$ $\mathrm{mm}$ rear/front, $\mathrm{L}=300 \mathrm{~mm}$ ) was used. PA 6 based nanocomposites filled with the different contents of the two aforementioned GNPs namely $0.5,1.5$, and 6.0 vol. \% of were produced. In addition, hybrid metal and nanofiller reinforced composites with 2.0 and 6.0 vol. \% of the two GNP nanofiller grades were prepared. During the compounding process, the temperature distribution was kept from 260 to $268{ }^{\circ} \mathrm{C}$ (feed section to die), with the average temperature of $264{ }^{\circ} \mathrm{C}$.

Injection molding of the nanocomposite specimens was performed on a Ferromatik, Milacron, USA following the instructions of ISO 294-1. The geometry of the cavity of the mold was ISO 527-2 2012 dog-bone shape. Constant cooling time of $15 \mathrm{~s}$ was applied for all the experiments. The thermal 
conductivity specimens were also compression molded (Carver, USA) into cylindrical specimens $($ diameter $=60 \mathrm{~mm}$, thickness $=10 \mathrm{~mm})$.

\subsection{Annealing}

In order to study the influence of annealing on the properties and microstructure of the produced composites, a series of annealing were conducted on the composites. In order to reach to an optimized annealing plan, annealing post-processes were initially performed on the metallic filler reinforced specimens. The electrical and thermal conductivity of the specimens were studied at different annealing times and temperatures under Nitrogen atmosphere. The considered annealing times were $2,4,6,8,10$, and 12 hours. Moreover, the applied annealing temperatures above the glass transition temperature of PA 6 included 100, 150, and $200^{\circ} \mathrm{C}$. The recognized best time and temperature leading to the highest conductivities were used for annealing process of the hybrid composites.

\subsection{Characterization}

The mechanical properties of the injection-molded specimens were characterized using uniaxial tensile experiments using a MTS 858, USA according to ISO 527-1 2012. At least, five samples were randomly selected from each batch of the produced specimens, and tested in the dry as molded state. The electrical conductivity experiments were performed on rectangular specimens $(50 \times 10 \times 3.8$ $\mathrm{mm}$ ). Electrical resistivity of the inner part was measured using two copper electrodes contacting the two ends of the test specimen under constant pressure using a Hewlett Packard multimeter, US. At least 10 random specimens were selected to conduct the experiments for each content.

The thermal conductivity experiments were conducted using an ISOMET 2104 (Applied Precision Ltd., Slovakia) device. The measurement was based on analysis of the temperature response of the analyzed material to heat flow impulses. The heat flow was excited by electrical heating of resistor heater inserted into the circular surface probe which is in direct heat contact with the specimens. Furthermore, in order to study the dispersion state and other possible involved mechanisms in the behavior of the nanocomposites produced via different methods, scanning electron microscopy (SEM) (Quanta FEG 200 ESEM) was employed on the fractured surfaces of the nanocomposites.

\section{Results and discussions}

\subsection{Metal filled composites}


The properties of the produced metal filler reinforced polymers were studied as a reference point in the studies. Table. 1 shows the characteristics of the produced metal filled composites. As it can be seen, the electrical conductivity of the metal filled samples produced by injection molding are in the order $10^{4}$. The thermal conductivity of the samples $\left(\mathrm{K}_{\text {thermal }}=2.26\right)$ are much higher that the neat PA $6\left(\mathrm{~K}_{\text {thermal }}=0.2\right)$.

Table 1. The properties of the metal filled polymers

\begin{tabular}{ccccc}
\hline Sample & $\begin{array}{c}\text { Elastic } \\
\text { modulus } \\
(\mathrm{MPa})\end{array}$ & $\begin{array}{c}\text { Tensile } \\
\text { strength }(\mathrm{MPa})\end{array}$ & $\begin{array}{c}\text { Electrical } \\
\text { conductivity } \\
(\mathrm{S} / \mathrm{m})\end{array}$ & $\begin{array}{c}\text { Thermal } \\
\text { conductivity } \\
\left(\mathrm{W} / \mathrm{m}^{\circ} \mathrm{K}\right)\end{array}$ \\
\hline PA 6 based composite & & & & \\
reinforced with 25 vol. \% & $3100 \pm 30$ & $25.6 \pm 0.4$ & $9921 \pm 360$ & $2.26 \pm 0.11$ \\
$\mathrm{Cu}$ and 19 vol. \% Tin-Zinc \\
alloy
\end{tabular}

Fig. 2 shows the morphology of the produced samples studied using optical light microscopy. As it was expected, the copper fibers are aligned along the flow of the polymer melt during the injection molding process. Moreover, the low melting alloy created a series additional connections resulting in the enhancement of thermal and electrical conductivities. However, a close look into the constructed networks revealed micro gaps in the conductive network. However, these minuscule gaps still enable electron tunneling mechanism, but the thin insulating polymeric layers hinder further conductivity enhancement. 

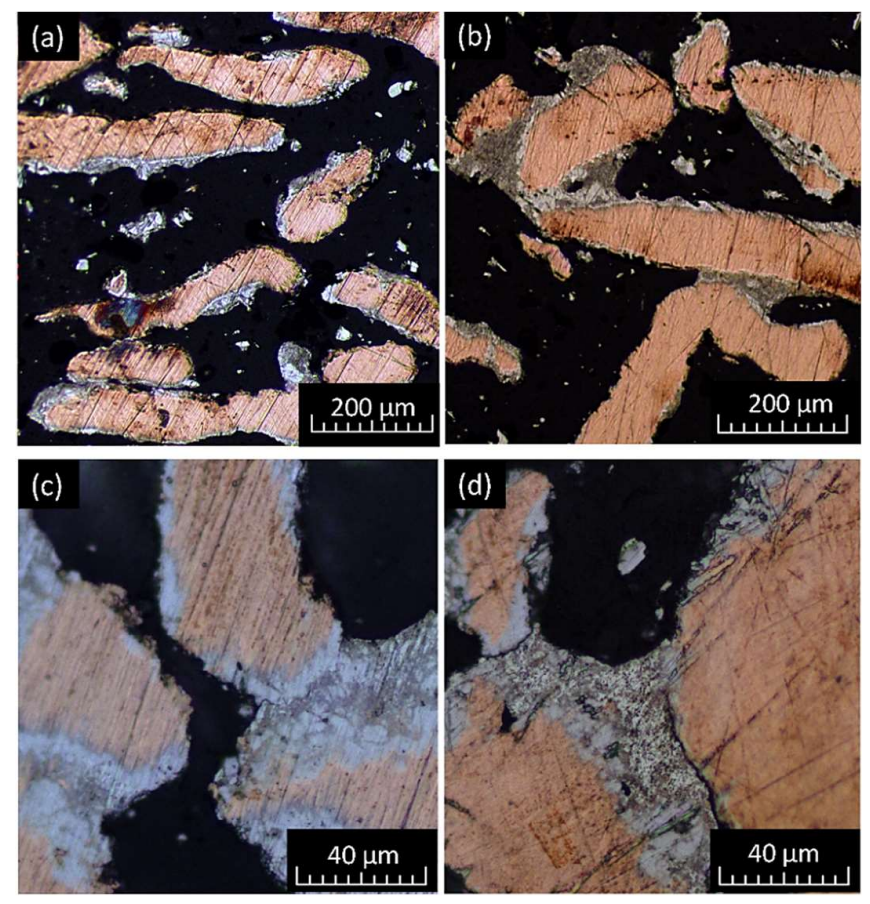

Fig. 2 Morphology of the produced metal filled composites: (a) oriented Copper fibers, (b) constructed conductive network, (c) and (d) micro cracks and gaps in the conductive network.

\subsection{Graphene filled composites}

The influence of incorporation of Graphene nanofillers on the properties of the PA 6 based composites was studied. Figs 3 (a) and (b) show the influence of GNP addition on the mechanical properties of the nanocomposites. Both GNP types enhanced the mechanical properties significantly. However, the thinner Graphene nanofillers acted much better in mechanical performance reinforcement. The elastic modulus of the nanocomposites containing 6.0 vol. \% of GNP C-500 and GNP H-15 increased 20 and $41 \%$, respectively. In fact, incorporation of thinner GNPs can theoretically lead to larger interfacial areas, which in turn strengthens the mechanical behaviors. The difference in the mechanical behaviors and the involved mechanisms were much more noticeable in tensile strengths where nanocomposites containing 6.0 vol. \% GNP H-15 showed nearly similar tensile strengths as neat PA 6. One can deduce that agglomerates of $\mathrm{H}-15$ prevailed the interfacial strengthening influence of Graphene nanofillers. Therefore, further enhancement in tensile strengths were prohibited in higher contents of GNP-H15, where intense stress concentrations around agglomerates led to premature brittle fracture in low strains. In fact, Graphene H-15 have more resemblance to graphite, and such deterioration in the strengths has been reported in other studies [25]. 

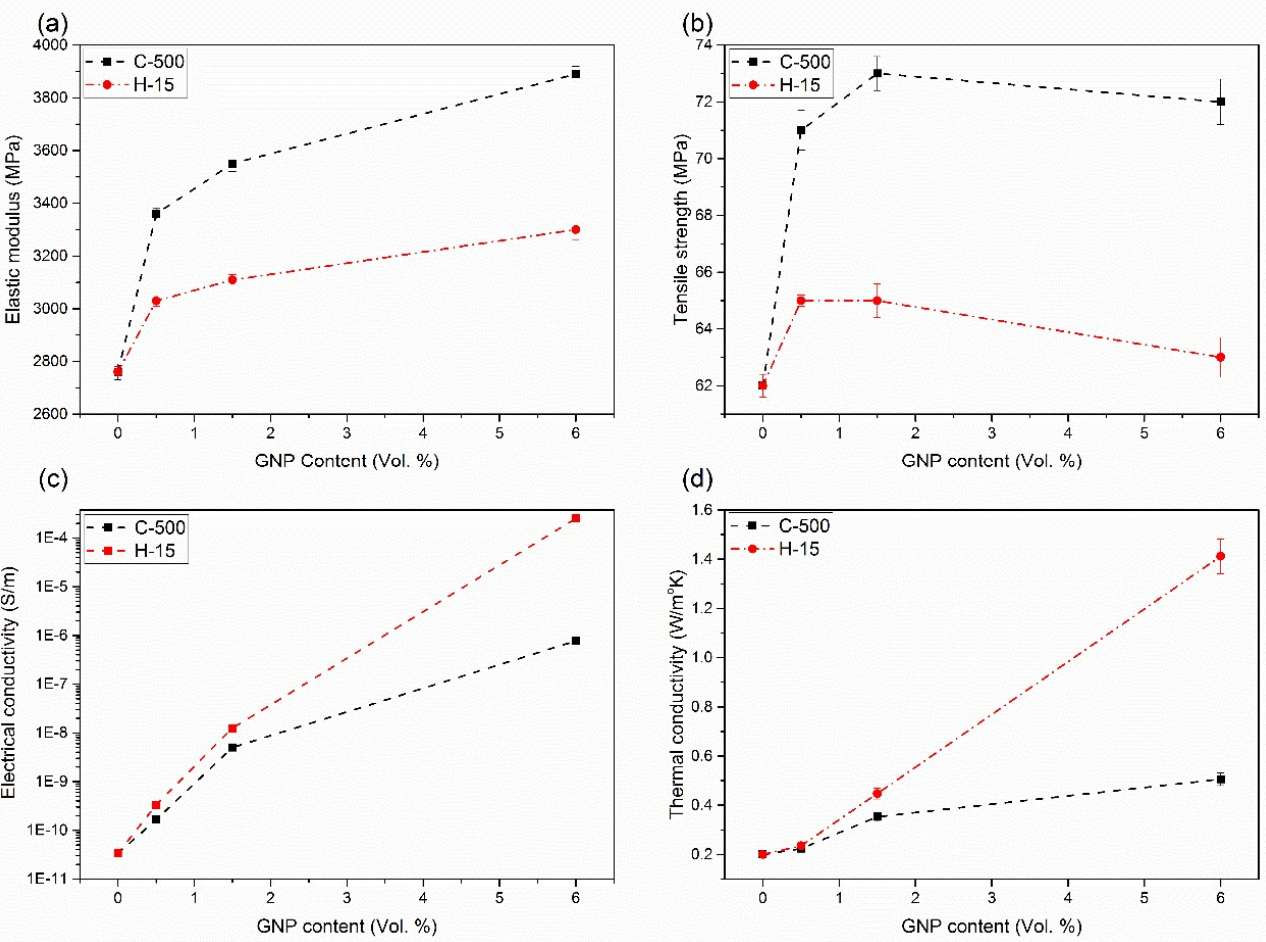

Fig. 3 Influence of GNP inclusion in the structure of PA 6: (a) elastic modulus, (b) tensile strength, (c) electrical, and (d) thermal conductivity.

Fig 3 (c) shows the influence of GNP inclusion on the electrical conductivity of the nanocomposites. The produced nanocomposites containing 0.5 and 1.5 vol. \% GNPs did not show notable increase in the electrical conductivity. However, with increasing the content of Graphene within the polymeric matrix, stronger electrical conductivities were observed. It should be noted that thicker Graphene fillers (Type H-15) acted much better in electrical conductivity enhancement. Similar behavior has also been reported in other studies [26]. In fact, despite showing fair level of electrical conductivity in 6.0 vol. \% of GNP inclusion, the nanocomposites are far from the desired conductivities suitable for many industrial applications. Fig. 3(d) shows the influence of the GNP on the thermal conductivity of the nanocomposites. Similar to electrical conductivities, inclusion of larger Graphene nanofillers results in composites with higher conductivities. Inclusion of 6.0 vol. \% GNP C-500 and H-15 within the polymer structure led to 150 and $600 \%$ enhancement in the thermal conductivities. It is also noteworthy to mention that while the rate of enhancement increased in higher contents of $\mathrm{H}-15$, the similar significant increase was not observed in higher contents of GNP C-500. The sharp enhancement rate of the GNP H-15 indicates the construction of a 3D conductive network of the nanofillers and increased number of direct contacts between the fillers. One might also attribute the significantly lower influence of GNP grade $\mathrm{C}$ on the conductivities to possible nanofiller defect 
density [26]. Moreover, it should be also noted that with decreasing the dimension of the nanofillers the probability of direct contacts and creating a path decreases especially in lower contents [27]. Therefore, such results even in absence of any defect on the filler can be expected from mathematics. Fig. 4 shows the positioning of the GNP nanofillers in the injection molded composites.
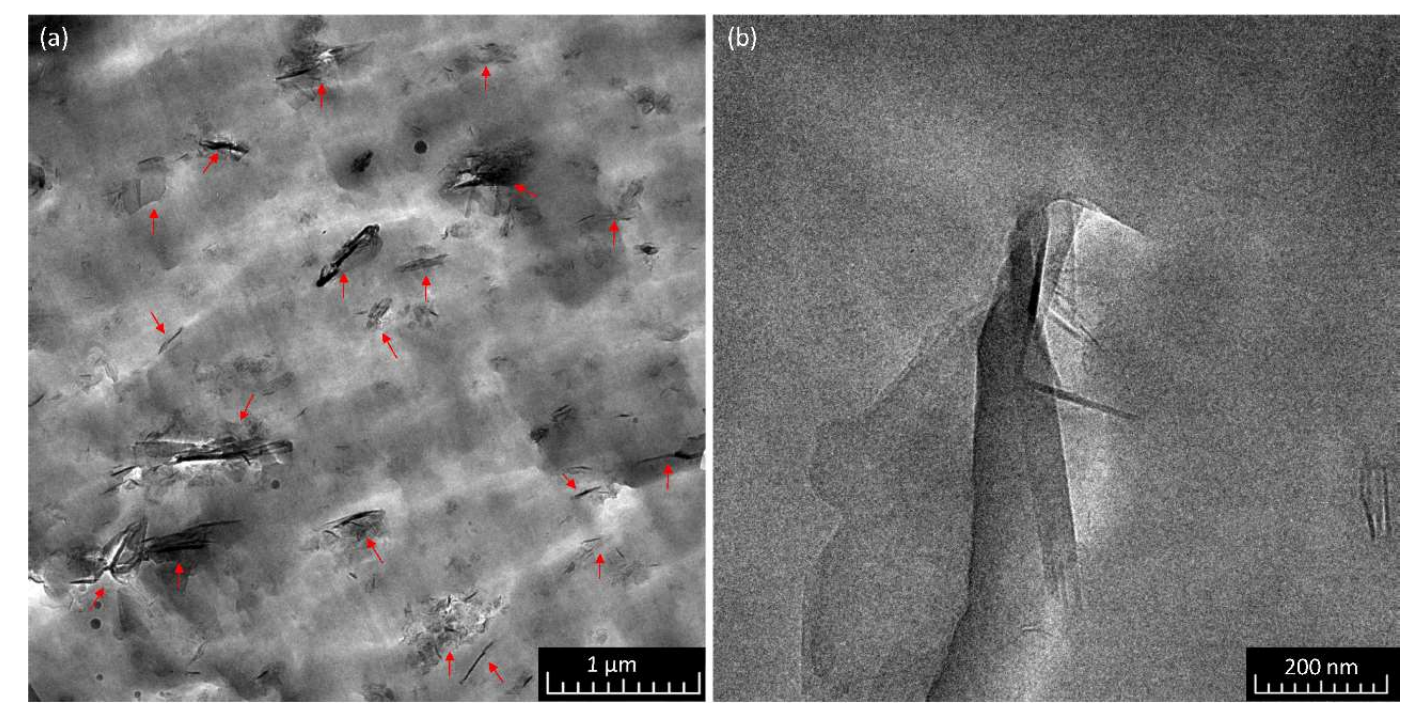

Fig. 4 TEM micrographs of GNP reinforced composites

\subsection{Hybrid metal-GNP composites}

Fig. 5 shows the mechanical behavior of metal and Graphene reinforced composites. As it can be seen in the figures, both elastic modulus and tensile strengths increased significantly. Similar to the characterized nanocomposites, inclusion of GNP grade C-500 resulted into better mechanical properties. 6.0 vol. \% GNP inclusion in the metal filled polymer resulted in $120 \%$ improvement in elastic modulus. In contrast to metallic or GNP filled composites where higher contents led to deterioration of the mechanics properties, the mechanical characteristics improved consistently. The combination of the two type of fillers compensated the deteriorated mechanical properties in the metal filled composites to some extent, where both elastic moduli and tensile strengths of the new hybrid composites improved. 

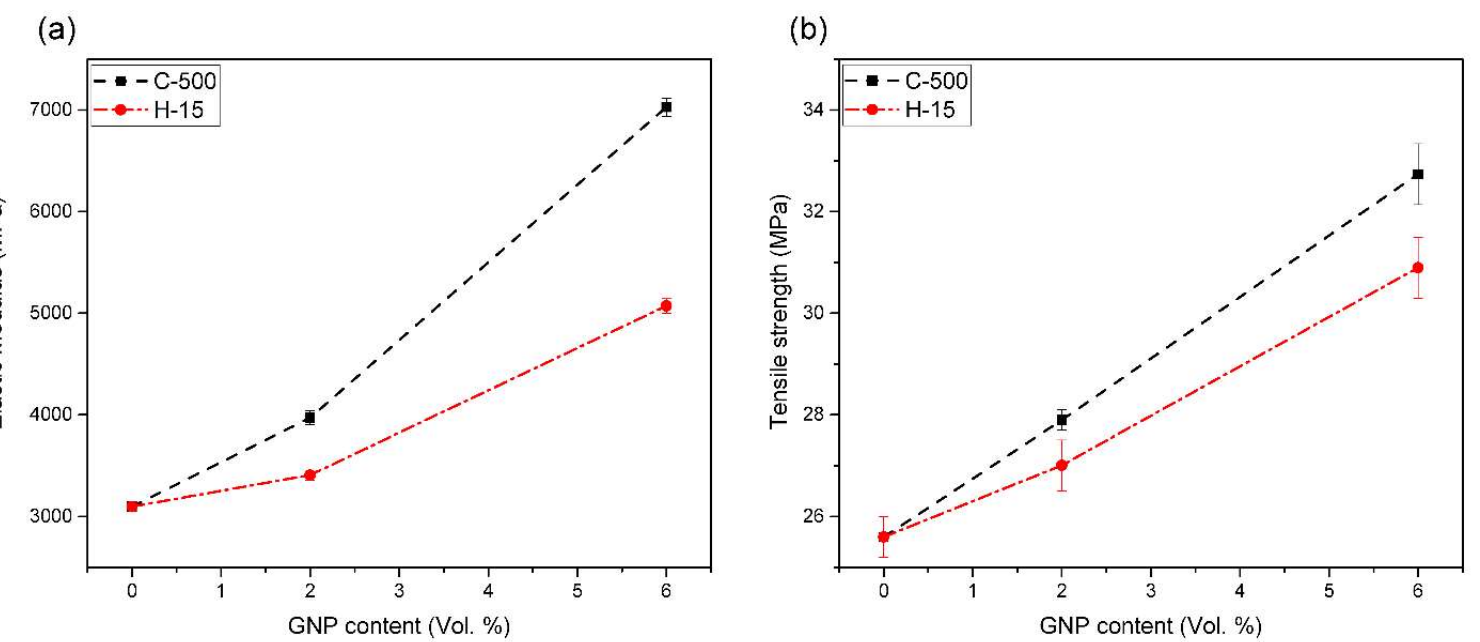

Fig. 5 The influence of GNP addition on the (a) elastic modulus, and (b) tensile strength of hybrid metal-GNP hybrid reinforced composites.

Fig. 6 shows the SEM graphs of fracture surfaces of the hybrid composites. The main failure mechanism of the copper fiber filled composites is debonding and fiber pull-out. In fact, the interface between the metallic fillers and the polymeric phase is not strong leading to lower tensile strengths. However, it seems that incorporation of Graphene nanofillers in the composites systems has strengthened the interface strength significantly. One can deduce that Graphene nanofillers have improved the bonding between the metallic part and the surrounding nanocomposites by increasing the friction. Therefore, higher fracture energy is required to overcome this additional bonding.
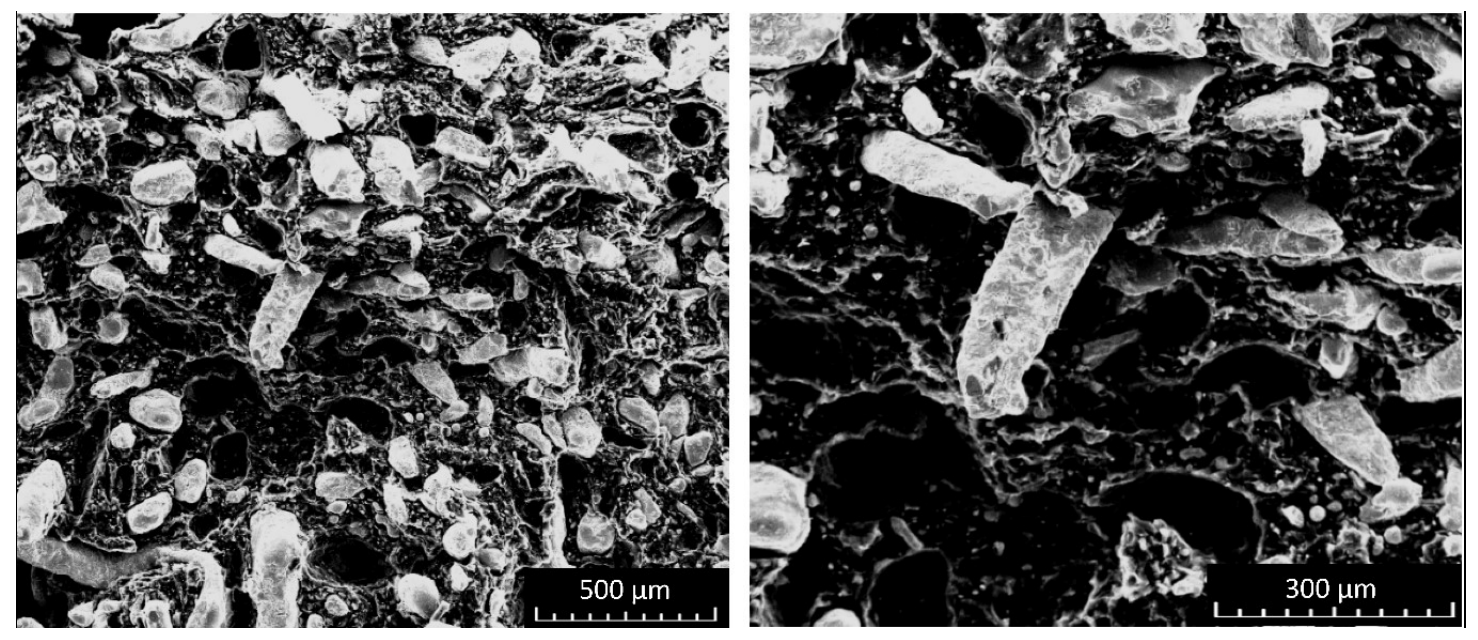

Fig. 6 The SEM pictures of fractured surfaces in hybrid composites. 
Fig. 7 shows the influence of GNP addition on the electrical and thermal performance of metal-GNP reinforced composites. Inclusion of both GNP nanofillers led to enhancement in electrical and thermal conductivities. Addition of $6.0 \mathrm{vol} . \%$ GNP in the composite structure led to 10 and $78 \%$ increase in electrical and thermal conductivities, respectively. It should be noted that while GNPs have not infiltrated into metallic phase, the polymeric phase contains all GNP nanofillers. Therefore, the effective GNP contents in the polymeric nanocomposites surrounding the metallic fillers are 4 and 10 vol. \%.

(a)

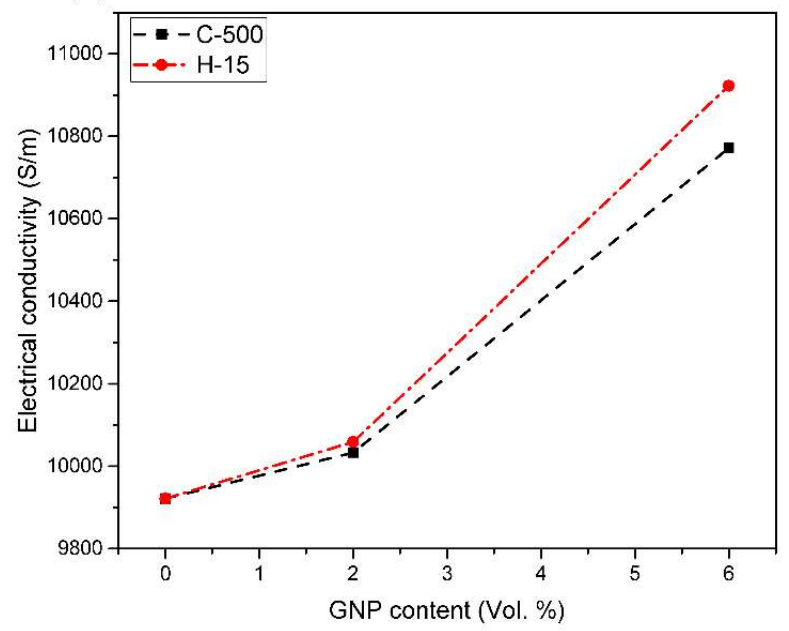

(b)

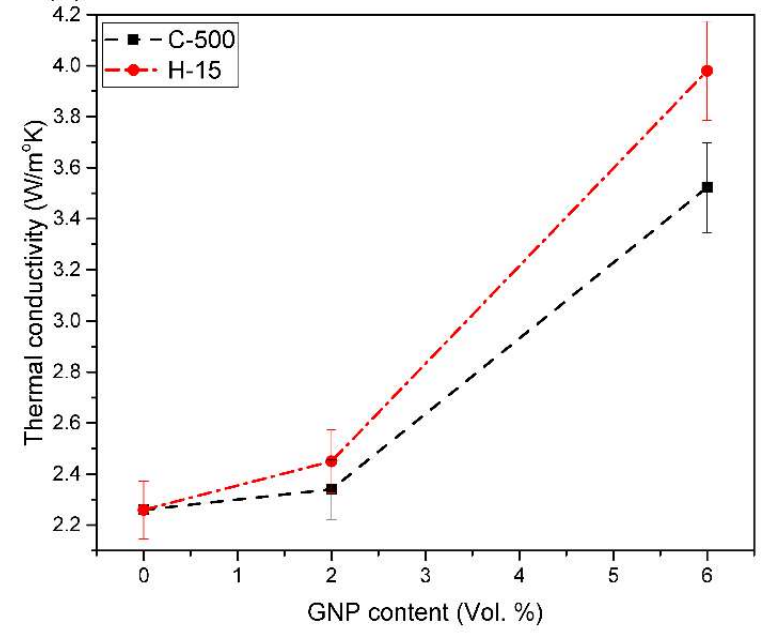

Fig. 7 The influence of GNP inclusion on the (a) electrical, and (b) thermal conductivities of the metal-GNP hybrid composites.

In order to understand the mechanism of additional improvement in the conductivities, the areas around the metallic fillers were studied using scanning electron microscopy. Fig. 8 shows the bridging mechanism of the nanofillers between the metallic fillers. The detected gaps in the network of the metals reflected sizes in the range of 3-40 $\mu \mathrm{m}$. In fact, nanofillers due to their smaller sizes can fill in these minuscule gaps between the metallic fillers. Therefore, additional connections became functional in the structure of the composites. However, this bridging mechanism based on size and characteristics of the nanofillers were different. Since GNPs grade C-500 have smaller sizes, one single Graphene platelet usually cannot fill in the gaps. In other words, a network of the Graphene nanofillers between the two metallic parts should be constructed before they can be effective. The presented results for the nanocomposites containing GNPs grade $\mathrm{C}$ showed that the constructed network is not effective enough. However, GNPs grade H-15 are much larger and could construct stronger 3D network in the lower contents. Therefore, one single GNP platelet or agglomerate of Graphene fillers could connect the gaps (See Fig. 8(d)). As the result of very high electron or phonon 
transport of Graphene layers, this additional contact lead to higher conductivities in the hybrid composites.
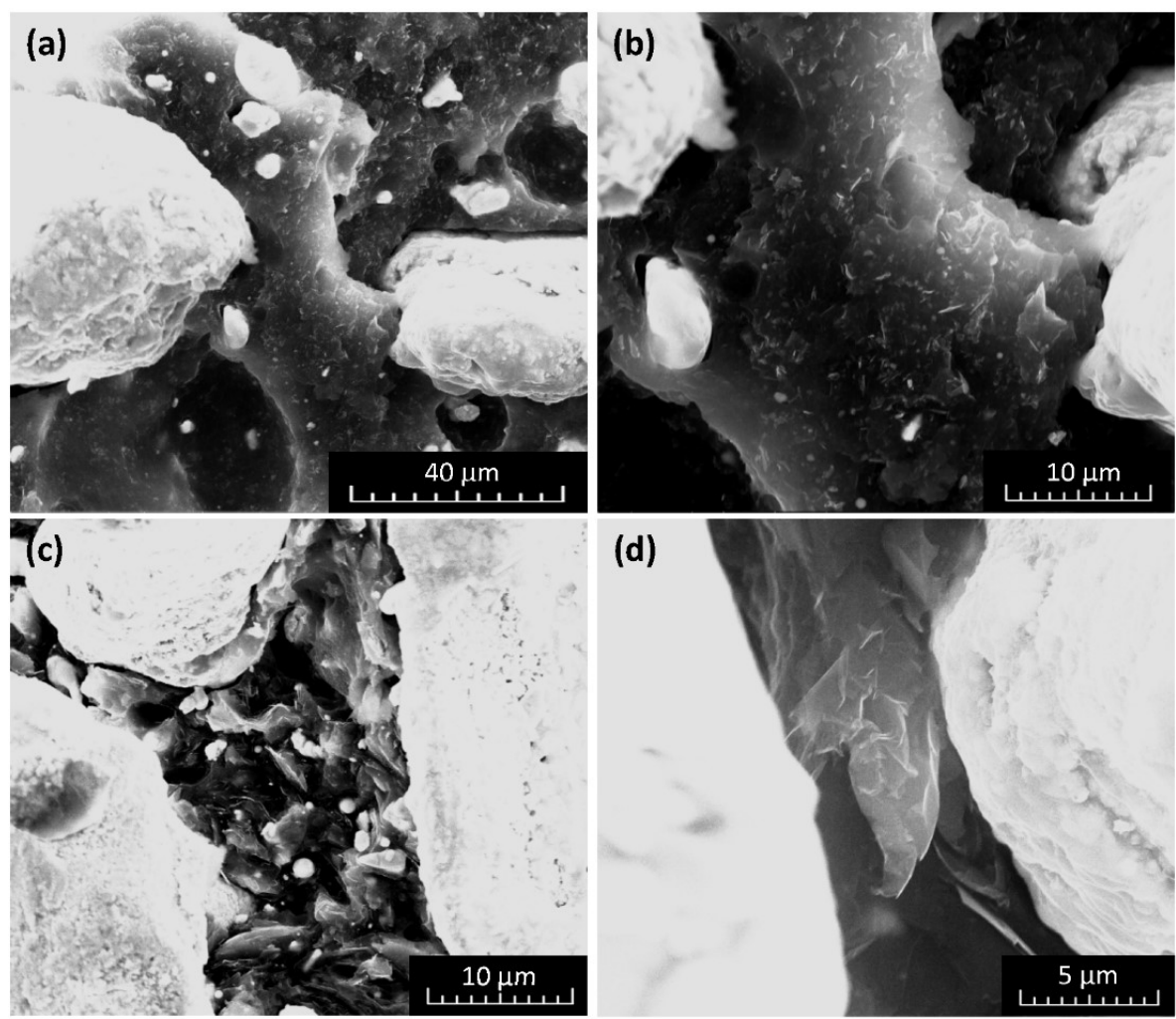

Fig. 8 SEM images of nanofiller bridging mechanism between metallic fillers by: (a) and (b) GNP grade C-500, and (c) and (d) GNP grade H-15.

\subsection{Annealing}

Moreover, since the electrical specimens were produced using injection molding process, fillers are oriented along the flow. This alignment of the fillers in the polymeric atmosphere reduces the number of possible contact between the fillers. Therefore, one can deduce that if the missed connections are reconstructed in the composite structure, the composites would deliver higher conductivities [28]. In order to reconstruct the lost contacts in the conductive network, an annealing post-process has been considered. Annealing post-process has been performed to re-orient the conductive fillers and to construct additional functional connections. Annealing at a temperature higher than the glass transition temperature of the PA 6 leads to stress relaxation of the composites system. The incorporated fillers are freed from their frozen state as the result of sharp cooling and high shear rates of the injection molding process. Fig. 9 shows the performed annealing on the composites to find the optimized time and temperature for the post-processes. Results showed that the conductivities 
increase with the duration of the process. However, after a peak in the properties, the results deteriorate again. And, the higher temperatures lead to faster achievement of this peak in the curves.

(a)

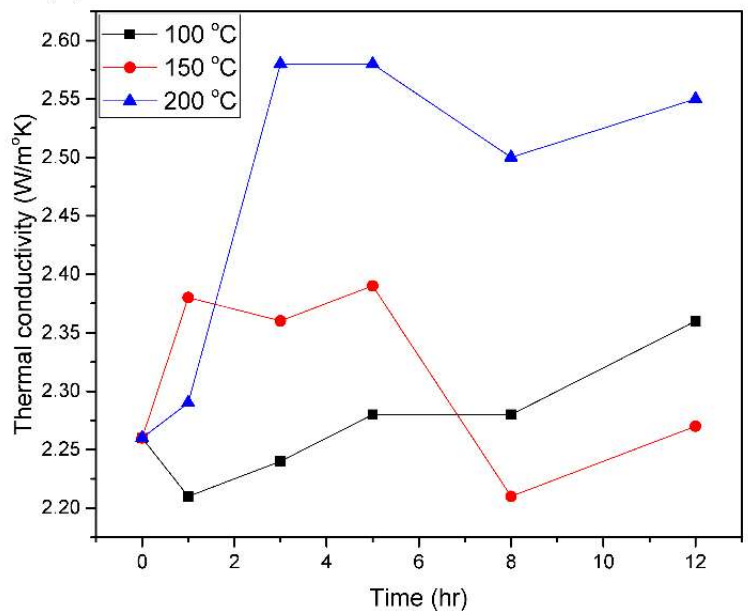

(b)

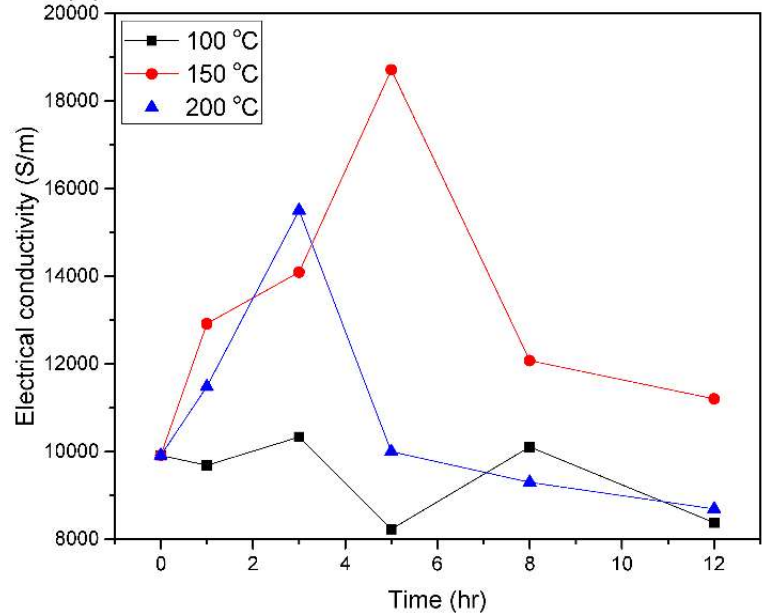

Fig. 9 Influence of annealing time and temperature on the (a) electrical, and (b) thermal conductivities of the metallic filler reinforced composites.

Fig. 10 shows the influence of annealing on electrical and thermal performance of the produced composites. As it can be seen from the diagrams, the electrical conductivities increased significantly after annealing indicating re-orientation of the fillers leading to additional conductive networks. Furthermore, it should be noted that the relative improvement increased in higher nanofiller contents. For instance, while the electrical conductivities in the composites reinforced with just metallic fillers improved $88 \%$ after annealing, hybrid composites containing 2.0 and 6.0 vol. \% GNP H-15 showed $95 \%$ and $129 \%$ improvement. This phenomenon shows that both types of fillers are influenced by the annealing process. In fact, annealing at temperatures above the glass transition temperatures of PA 6 provide the opportunity for both fillers to construct better networks between themselves or each other in the amorphous phase. Moreover, Graphene type H-15 showed further enhancement in the electrical conductivities after annealing compared to GNP type C-500.

However, the observed significant improvements in the electrical behavior were not observed in the thermal conductivities. In fact, since the thermal conductivity specimens were produced by compression molding, induced orientations did not exist in their structure. In fact, the conductivity behaviors of the specimens have already benefited from their random microstructure, and the networks have already been available there. 

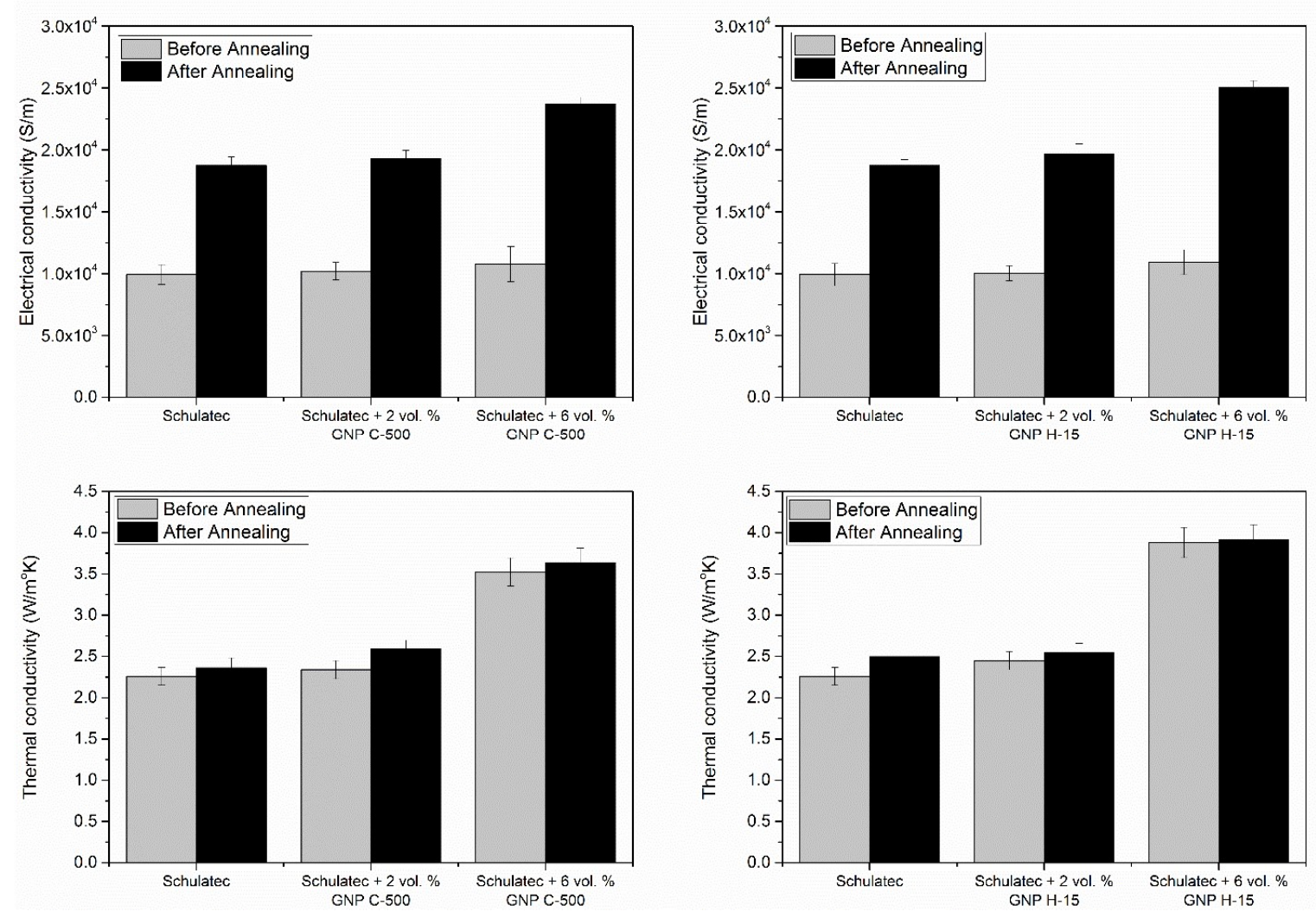

Fig. 10 Influence of annealing on the (a), (b) electrical conductivities, and (c) and (d) thermal conductivities of the hybrid composites.

\section{Conclusions}

Processing, properties, and post-processing of conductive polymeric composites were investigated. Different kinds and combinations of conductive fillers were included in the polymeric composites. Results showed that inclusion of Graphene nanofillers within the structure of polymeric matrix lead to enhancement of mechanical, thermal and electrical performances. High thermal conductivities can be achieved with the addition of the GNP nanofillers in the polymeric structure. However, the acquired electrical conductivities might just be suitable for electrostatic or antistatic applications. The results showed that thicker and larger Graphene fillers act much better as conductivity reinforcement agents due to higher probability of constructing conductive networks. In addition, the combination of the metallic fillers and carbon nanofillers enhances the properties significantly. Mechanical properties benefitted from the strengthened interface in the composites, and showed significantly improved results. Moreover, the new conductive bridges as the result of GNP addition increased both thermal and electrical conductivities of the metal reinforced composites. This phenomenon in presence of 
larger GNP fillers where they can fill in the micro gaps was more effective. In addition, the performed annealing increased the electrical conductivities in the specimens manufactured by injection molding notably. Inclusion of nanofillers and performing annealing on the hybrid metal and Graphene filled hybrid composites increased electrical and thermal conductivities 251 and $72 \%$ compared to the produced metal filled composites.

\section{References}

1. Mamunya, Y. P., Davydenko, V. V, Pissis, P. \& Lebedev, E. V. Electrical and thermal conductivity of polymers filled with metal powders. European Polymer Journal, 38, 1887-1897 (2002).

\section{https://doi.org/10.1016/S0014-3057(02)00064-2}

2. Bauhofer, W. \& Kovacs, J. Z. A review and analysis of electrical percolation in carbon nanotube polymer composites. Composites Science and Technology, 69, 1486-1498 (2009). https://doi.org/10.1016/j.compscitech.2008.06.018

3. Sengupta, R., Bhattacharya, M., Bandyopadhyay, S. \& Bhowmick, A. K. A review on the mechanical and electrical properties of graphite and modified graphite reinforced polymer composites. Progress in Polymer Science, 36, 638-670 (2011).

https://doi.org/10.1016/j.progpolymsci.2010.11.003

4. Lux, F. Models proposed to explain the electrical conductivity of mixtures made of conductive and insulating materials. Journal of Materials Science, 28, 285-301 (1993). https://doi.org/10.1007/BF00357799

5. Weber, M. \& Kamal, M. R. Estimation of the volume resistivity of electrically conductive composites. Polymer Composites, 18, 711-725 (1997).

http://dx.doi.org/10.1002/pc.10324

6. Deng, Hua, Lin, Lin, Ji, Mizhi, Zhang, Shuangmei, Yang, Mingbo \& Fu, Qiang. Progress on the morphological control of conductive network in conductive polymer composites and the use as electroactive multifunctional materials. Progress in Polymer Science, 39, 627-655 (2014). https://doi.org/10.1016/j.progpolymsci.2013.07.007

7. Chen, Hongyu, Ginzburg, Valeriy V, Yang, Jian, Yang, Yunfeng, Liu, Wei, Huang, Yan, $\mathrm{Du}$, Libo \& Chen, Bin. Thermal conductivity of polymer-based composites: Fundamentals and applications. Progress in Polymer Science, 59, 41-85 (2016). 
https://doi.org/10.1016/j.progpolymsci.2016.03.001

8. Ch. Hopmann, J. Fragner, Stefan Haase. Development of electrically conductive plastic compounds based on filler combinations. Journal of Plastics Technology, 10, 49-67 (2014).

9. Michaeli, Walter, Hopmann, Christian, Fragner, Jan \& Pfefferkorn, Tobias. Injection molding of conductor paths: integration of functionality by the use of a metal/thermoplastic hybrid material. Journal of Polymer Engineering, 31, 479-487 (2011).

https://doi.org/10.1515/POLYENG.2011.092

10. Lin, Yaxue, Jia, Yuting, Alva, Guruprasad \& Fang, Guiyin. Review on thermal conductivity enhancement, thermal properties and applications of phase change materials in thermal energy storage. Renewable and Sustainable Energy Reviews, (2017).

https://doi.org/10.1016/j.rser.2017.10.002

11. Cipriano, Bani H., Kota, Arun K., Gershon, Alan L., Laskowski, Conrad J., Kashiwagi, Takashi, Bruck, Hugh A. \& Raghavan, Srinivasa R. Conductivity enhancement of carbon nanotube and nanofiber-based polymer nanocomposites by melt annealing. Polymer, 49, 4846-4851 (2008). https://doi.org/10.1016/j.polymer.2008.08.057

12. Verdejo, Raquel, Bernal, M.Mar, Romasanta, Laura J. \& Lopez-Manchado, Miguel A. Graphene filled polymer nanocomposites. Journal of Materials Chemistry, 21, 3301-3310 (2011). https://doi.org/10.1039/C0JM02708A

13. Bilotti, Emiliano, Zhang, Han, Deng, Hua, Zhang, Rui, Fu, Qiang \& Peijs, Ton. Controlling the dynamic percolation of carbon nanotube based conductive polymer composites by addition of secondary nanofillers: the effect on electrical conductivity and tuneable sensing behaviour. Composites Science and Technology, 74, 85-90 (2013).

https://doi.org/10.1016/j.compscitech.2012.10.008

14. Socher, Robert, Krause, Beate, Hermasch, Sylvia, Wursche, Roland \& Pötschke, Petra. Electrical and thermal properties of polyamide 12 composites with hybrid fillers systems of multiwalled carbon nanotubes and carbon black. Composites Science and Technology, 71, 10531059 (2011).

https://doi.org/10.1016/j.compscitech.2011.03.004

15. Zhou, T., Wang, X., Cheng, P., Wang, T. \& Xiong, D. Improving the thermal conductivity of epoxy resin by the addition of a mixture of graphite nanoplatelets and silicon carbide microparticles. Express Polymer Letters, 7, (2013).

http://dx.doi.org/10.3144/expresspolymlett.2013.56 
16. Yoo, Youngjae, Lee, Hoing Lae, Ha, Sung Min, Jeon, Byung Kuk, Won, Jong Chan \& Lee, Sung - Goo. Effect of graphite and carbon fiber contents on the morphology and properties of thermally conductive composites based on polyamide 6. Polymer International, 63, 151-157 (2014). http://dx.doi.org/10.1002/pi.4534

17. Balandin, Alexander A. Thermal properties of graphene and nanostructured carbon materials. Nature materials, 10, 569-581 (2011).

http://dx.doi.org/10.1038/nmat3064

18. Marinho, Bernardo, Ghislandi, Marcos, Tkalya, Evgeniy, Koning, Cor E. \& de With, Gijsbertus. Electrical conductivity of compacts of graphene, multi-wall carbon nanotubes, carbon black, and graphite powder. Powder technology, 221, 351-358 (2012).

https://doi.org/10.1016/j.powtec.2012.01.024

19. Hu, Kesong, Kulkarni, Dhaval D., Choi, Ikjun \& Tsukruk, Vladimir V. Graphene-polymer nanocomposites for structural and functional applications. Progress in Polymer Science, 39, 19341972 (2014).

https://doi.org/10.1016/j.progpolymsci.2014.03.001

20. Mayoral, Beatriz, Harkin-Jones, Eileen, Khanam, P.Noorunnisa, AlMaadeed, M. A., Ouederni, Mabrouk, Hamilton, A. R. \& Sun, Dan. Melt processing and characterisation of polyamide 6/graphene nanoplatelet composites. RSC Advances, 5, 52395-52409 (2015). https://doi.org/10.1039/C5RA08509H

21. Mittal, Garima, Dhand, Vivek, Rhee, Kyong Yop, Park, Soo-Jin \& Lee, Wi Ro. A review on carbon nanotubes and graphene as fillers in reinforced polymer nanocomposites. Journal of Industrial and Engineering Chemistry, 21, 11-25 (2015).

https://doi.org/10.1016/j.jiec.2014.03.022

22. Hu, Z., Tong, G., Lin, D., Chen, C., Guo, H., Xu, J. \& Zhou, L. Graphene-reinforced metal matrix nanocomposites-a review. Materials Science and Technology, 32, 930-953 (2016). https://doi.org/10.1080/02670836.2015.1104018

23. Wejrzanowski, Tomasz, Grybczuk, Mateusz, Chmielewski, Marcin, Pietrzak, Katarzyna, Kurzydlowski, K. J. \& Strojny-Nedza, A. Thermal conductivity of metal-graphene composites. Materials \& design, 99, 163-173 (2016).

https://doi.org/10.1016/j.matdes.2016.03.069 
24. Pavithra, Chokkakula L. P., Sarada, Bulusu V, Rajulapati, Koteswararao V, Rao, Tata N. \& Sundararajan, G. A new electrochemical approach for the synthesis of copper-graphene nanocomposite foils with high hardness. Scientific reports, 4, (2014).

https://doi.org/10.1038/srep04049

25. Uhl, Fawn M., Yao, Qiang, Nakajima, Hiroyoshi, Manias, E. \& Wilkie, Charles A.

Expandable graphite/polyamide-6 nanocomposites. Polymer Degradation and Stability, 89, 70-84 (2005).

https://doi.org/10.1016/j.polymdegradstab.2005.01.004

26. Shtein, Michael, Nadiv, Roey, Buzaglo, Matat, Kahil, Keren \& Regev, Oren. Thermally conductive graphene-polymer composites: size, percolation, and synergy effects. Chemistry of Materials, 27, 2100-2106 (2015).

https://doi.org/10.1021/cm504550e

27. Descamps, Pierre, Van Wassenhove, G., Teixeira, S. \& Beaucarne, G. Using a Monte-Carlo model to identify best filler arrangement in thermally conductive materials. Microelectronics Journal, 46, 1179-1184 (2015).

https://doi.org/10.1016/j.mejo.2015.06.026

28. Palza, H., Garzón, C. \& Arias, O. Modifying the electrical behaviour of

polypropylene/carbon nanotube composites by adding a second nanoparticle and by annealing processes. Express Polym. Lett, 6, 639-646 (2012).

http://dx.doi.org/10.3144/expresspolymlett.2012.68 